\title{
Release of EPA and DHA from salmon oil - a comparison of in vitro digestion with human and porcine gastrointestinal enzymes
}

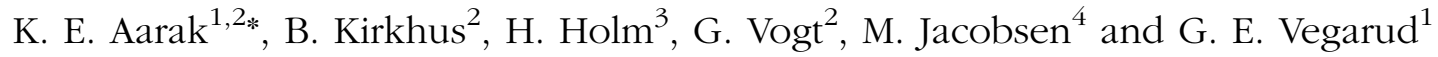 \\ ${ }^{1}$ Department of Chemistry, Biotechnology and Food Science (IKBM), Chr. M. Falsens vei 1, BTB, \\ Norwegian University of Life Sciences, 1432 As, Norway \\ ${ }^{2}$ Nofima AS, Norwegian Institute of Food, Fisheries and Aquaculture Research, Ås, Norway \\ ${ }^{3}$ Department of Nutrition, University of Oslo, Institute for Basic Medical Science, O316 Oslo, Norway \\ ${ }^{4}$ Oestfold Hospital Trust, Fredrikstad, Norway \\ (Submitted 30 October 2012 - Final revision received 30 January 2013 - Accepted 31 January 2013 - First published online 19 March 2013 )
}

\section{Abstract}

In the present study, we hypothesised whether in vitro digestion of salmon oil would release different amounts of PUFA depending on the origin of the lipolytic enzymes used. For this purpose, in vitro digestion of salmon oil (SO) was performed using human duodenal juice (HDJ) or a commercial enzyme preparation consisting of porcine pancreatin and bile (PB). The lipolytic effect was determined by measuring the release of fatty acids (FA) using solid-phase extraction and GC-flame ionisation detection, withdrawing samples every 20 min during digestion. The amount of FA released indicated that a plateau was reached after 80 min with approximately similar amounts of FA detected using both HDJ and PB (379 (SD 18) and 352 (SD 23) mg/g SO, respectively). However, the release of 18:2, EPA (20:5) and DHA (22:6) was significantly different during in vitro digestion. At 80 min, HDJ and PB released 43 and $33 \%$ of $18: 2,14$ and $9 \%$ of EPA and 11 and $9 \%$ of DHA, respectively. Both enzyme preparations released approximately the same amounts of the other FA analysed. The effect of the addition of bile salts (BS) was significantly different in the two enzyme systems, where porcine pancreatin highly responded to the increase in BS concentration, in contrast to HDJ.

Key words: DHA: EPA: Human and porcine gastrointestinal enzymes: In vitro lipid digestion: Lipolysis: n-3 PUFA: Salmon oil

There is an increasing interest in using in vitro digestion models, both to understand how food is being digested and to simulate human digestion; thus, many approaches have been suggested and designed for different purposes. A recent review by Hur et $a l .{ }^{(1)}$ has shown large variations in existing models, concerning variables such as $\mathrm{pH}$, use of one, two or more gastrointestinal phases, enzyme sources and chemicals used. In vitro-in vivo correlations in digestion models are important. Despite this, most models still need validation with human data, and there is an urgent need for developing more physiologically relevant models ${ }^{(2)}$. To better simulate human physiological conditions, one approach is to aspirate gastrointestinal juices from human volunteers to be used in in vitro models. Previously, human aspirates have been used in several in vitro studies to investigate protein degradation and to detect the formation of bioactive peptides ${ }^{(3-6)}$. However, few studies have been conducted on lipid digestion ${ }^{(7)}$, and to our knowledge, no comparisons of commercial $v$. human gastrointestinal enzymes for this purpose have been performed.
The mechanisms of lipid breakdown during digestion, including the release of specific fatty acids (FA) and their bioaccessibility in the gut, are important to understand due to the various health implications of lipids ${ }^{(8)}$. The health benefits of the $n$-3 long-chain PUFA ( $n$-3 LC-PUFA) EPA (20:5) and DHA (22:6) have been well documented with regard to reducing the risk of CVD and having a positive effect on autoimmunity and mental disorders ${ }^{(9-14)}$. Salmon is an important source of these FA in the human diet ${ }^{(15)}$, and salmon oil (SO) was therefore chosen as a substrate in the present study. As reviewed by McClements \& $\mathrm{Li}^{(16)}$, lipid digestion has been reported to be more complex than protein digestion, both with regard to enzymes and to physiological conditions in the gut $^{(17-20)}$. Several factors could affect the hydrolysis of dietary lipids, such as food matrix and buffering capacity, type of emulsion (oil in water or water in oil) and individual secretion of both digestive enzymes and bile salts (BS) ${ }^{(21-26)}$. In humans, three lipolytic enzyme systems are important for lipid digestion: lingual, gastric and pancreatic lipase systems ${ }^{(27)}$.

Abbreviations: BS, bile salts; FA, fatty acids; HDJ, human duodenal juice; LC-PUFA, long-chain PUFA; PB, pancreatin and bile; SO, salmon oil. 
These are responsible for hydrolysing FA from specific positions on TAG ( $s n-1,-2$ and -3$)$.

Lingual and gastric lipases are secreted in the mouth and in the fundic region of the gastric ventricle, respectively ${ }^{(28,29)}$. They are both active in the stomach and might be responsible for $10-30 \%$ of dietary lipid hydrolysis ${ }^{(20,21)}$ and the limited extent of gastric lipolysis has been suggested to be due to feedback inhibition by lipid products ${ }^{(17,30,31)}$. Lingual and gastric lipases hydrolyse only one position on each TAG, and has a preference for the $s n-1$ and $s n-3$ positions, but also a limited $s n-2$ activity $^{(32)}$. This lipolytic activity, yielding one NEFA and one diacylglycerol ${ }^{(17,33-35)}$, gives a more efficient fat emulsification with $\mathrm{BS}^{(19,20)}$, helping large lipid droplets to disperse into smaller micelles ${ }^{(36)}$. The formation of micelles facilitates subsequent duodenal TAG hydrolysis by pancreatic lipases ${ }^{(37)}$, and is a prerequisite for further lipolysis in the duodenum. Pancreatic lipase, which is the main enzyme system responsible for lipolysis in the human gastrointestinal tract, hydrolyses about $95-98 \%$ of the remaining dietary $\mathrm{TAG}^{(38)}$. This enzyme system has a preference for FA located in the $s n-1$ and $s n-3$ positions of TAG $^{(39,40)}$, yielding two NEFA plus one $s n-2$ monoacylglycerol ${ }^{(39,41)}$. Pancreatic lipase is inhibited by surface-active agents from the bile ${ }^{(36,42-44)}$, mainly the bile acids (cholic acid, deoxycholic acid and chenodeoxycholic acid) ${ }^{(8)}$, which are the protonated form of the BS. To overcome the inhibition facilitated by BS, colipase is necessary as a mediator ${ }^{(42,45)}$. Colipase anchors pancreatic lipase to its substrate $^{(46)}$ by binding both pancreatic lipase ${ }^{(47,48)}$ and $\mathrm{BS}^{(49)}$, helping the lipolytic activity to proceed.

The present study aimed to compare two different enzyme sources, human duodenal juice (HDJ) and porcine pancreatin plus bile mix (PB), on the in vitro duodenal digestion of $\mathrm{SO}$, to reveal differences in mechanisms by the two different lipolytic enzyme systems. SO has a naturally high content of the two $n$-3 LC-PUFA, EPA and DHA, which are known to be of nutritional importance. Consequently, it was of importance to study the specificity of the enzyme systems used, the kinetics of the reaction and the liberation of these specific FA as well.

\section{Experimental methods}

\section{Chemicals and materials}

SO from Atlantic salmon (Salmo salar L.) was obtained from Denomega (Denomega Nutritional Oils), and the lipid composition is described in Table 1. Pancreatin (porcine, EC no.: 232-468-9) and bile extract (ovine and bovine, EC no.: 232-369-0) were obtained from Sigma Chemical Company. Human duodenal enzymes were obtained by collecting HDJ from six persons according to Ulleberg et al. ${ }^{(50)}$ and Holm et $a{ }^{(51)}$. In brief, a three-lumen tube (Maxter Catheters) enabled both simultaneous instillation of a stimulation solution in the duodenum and aspiration of gastric and duodenal juices. The stimulation solution (sucrose $70 \mathrm{~g} / \mathrm{l}, \mathrm{NaCl} 1.8 \mathrm{~g} / \mathrm{l}$, L-phenylalanine $3.2 \mathrm{~g} / \mathrm{l}$ and L-valine in water $2.3 \mathrm{~g} / \mathrm{l}$ ) was instilled close to the papilla of Vateri $(100 \mathrm{ml} / \mathrm{h})$ to stimulate the production of pancreatic enzymes. HDJ was aspirated
Table 1. Lipid composition of oil from Atlantic salmon (SO, Salmo salar L.)

\begin{tabular}{lc}
\hline$F A$ & SO $(\mathrm{g} / 100 \mathrm{~g})$ \\
\hline $14: 0$ & $5 \cdot 0$ \\
$14: 1$ & $0 \cdot 0$ \\
$16: 0$ & $13 \cdot 0$ \\
$16: 1$ & $5 \cdot 1$ \\
$18: 0$ & $2 \cdot 8$ \\
$18: 1 n-9$ & $28 \cdot 3$ \\
$18: 1 n-7$ & $3 \cdot 4$ \\
$18: 2$ & $8 \cdot 8$ \\
$18: 3$ & $3 \cdot 7$ \\
$20: 0$ & $0 \cdot 2$ \\
$20: 1$ & $5 \cdot 5$ \\
$20: 2$ & $1 \cdot 1$ \\
$20: 4$ & $0 \cdot 4$ \\
$22: 0$ & $1 \cdot 1$ \\
$22: 1$ & $3 \cdot 8$ \\
$20: 5$ & $6 \cdot 1$ \\
$24: 0$ & $0 \cdot 2$ \\
$24: 1$ & $0 \cdot 3$ \\
$22: 5$ & $2 \cdot 4$ \\
$22: 6$ & $8 \cdot 9$ \\
\hline
\end{tabular}

FA, fatty acids.

approximately $10 \mathrm{~cm}$ distally. Aspirates were collected on ice, centrifuged $(4500 \mathrm{~g}, 10 \mathrm{~min})$ to remove mucus and cell debris before being frozen in batches and stored at $-20^{\circ} \mathrm{C}$ before use. This study was conducted according to the guidelines laid down in the Declaration of Helsinki and all procedures involving human subjects/patients were approved by Norwefian Regional Ethics Committee, REK. Approved by project no. 2012/2230 and Biobank no. 2012/2230. All subjects signed up as volunteers in the project.

\section{Total protein content}

Total protein concentrations were measured in triplicate using the [Q]Qubit ${ }^{\mathrm{TM}}$ Fluorometer (Invitrogen) with the Quant-ITTM protein assay kit (Invitrogen) according to the manufacturer's instructions.

\section{In vitro digestion}

The in vitro digestion model employed was based on duodenal digestion described by Aura et al. ${ }^{(52)}$. A procedure was developed for using HDJ $(1.37 \mathrm{mg}$ protein $/ \mathrm{ml}$, diluted with $0 \cdot 15 \mathrm{M}-\mathrm{NaHCO}_{3}$ ) or a commercial porcine enzyme mix, PB $(1.2 \mathrm{mg}$ pancreatin $/ \mathrm{ml}$ and $11.8 \mathrm{~mm}-\mathrm{BS}$ in $0.9 \% \mathrm{NaCl}$ and $0 \cdot 15 \mathrm{M}-\mathrm{NaHCO}_{3}$ ). For each time point, one tube was prepared, each tube containing, in total, $8.1 \mathrm{ml}$ of the respective enzyme solutions. $\mathrm{pH}$ was adjusted to $7 \cdot 0$ before the tubes were placed in a rotary incubator $\left(37^{\circ} \mathrm{C}, 215 \mathrm{rpm}\right)$ for $15 \mathrm{~min}$, followed by the addition of $0 \cdot 125 \mathrm{~g}$ SO. After incubation for $0,20,40$, 60, 80 and $110 \mathrm{~min}$, the tubes were placed on ice and $\mathrm{CHCl}_{3}$-methanol (2:1) was added in order to stop lipid hydrolysis. The digestion experiments were carried out in duplicate or more, except for the incubations at $110 \mathrm{~min}$, which were examined only once due to the lack of material.

In order to optimise the procedure, the experiments were performed by varying the substrate concentration (SO) from 
4.5 to $38.0 \mathrm{mg} / \mathrm{ml}$ for the commercial PB system, the commercial porcine pancreatin concentration from 1.4 to $13.6 \mathrm{mg} / \mathrm{ml}$ and the BS concentration from 0 to $118 \mathrm{~mm}$ for both enzyme systems (pancreatin and HDJ). The experiments were carried out in duplicate or more.

\section{Lipid extraction and analysis}

Lipids were extracted from the digesta according to Bligh \& Dyer $^{(53)}$ and separated into lipid classes, i.e. NEFA, neutral lipids (monoacylglycerol, diacylglycerol and TAG) and polar lipids, using an automated solid-phase extraction (Gerstel MPS Autosampler; Gerstel $\mathrm{GmbH}$ ) based on a modified and in-house validated method ${ }^{(54)}$. Internal standards, C23 (NEFA) and C21 (TAG), were used for the quantification of FA in the NEFA and neutral lipid fractions, respectively. Neutral lipids were eluted with $\mathrm{CHCl}_{3}-$ methanol, and NEFA with diethyl ether-acetic acid. The solvent was removed by evaporation under $\mathrm{N}_{2}$, and the contents of FA in the fractions were measured as FA methyl esters using GC with flame ionisation detection. Briefly, the lipids were derivatised and analysed as methyl esters using an Agilent 6890 capillary gas chromatograph (GC) equipped with a BPX-70 column (60 $\mathrm{m} \times 0.25 \mathrm{~mm}$ inner diameter, $0.25 \mu \mathrm{m}$ film; SGE Analytical Science Private Limited). The temperature program started at $70^{\circ} \mathrm{C}$ for $1 \mathrm{~min}$, increased by $30^{\circ} \mathrm{C} / \mathrm{min}$ to $170^{\circ} \mathrm{C}, 1.5^{\circ} \mathrm{C} / \mathrm{min}$ to $200^{\circ} \mathrm{C}$ and $3^{\circ} \mathrm{C} / \mathrm{min}$ to $220^{\circ} \mathrm{C}$ with a final hold time of $5 \mathrm{~min}$. Peaks were integrated with Agilent GC ChemStation software (version A.05.02; Agilent Technologies), and identified using external standards. Coefficients of variation were $<5 \%$. Hydrolysis was measured as mg NEFA/g SO added.

\section{Bile salt concentration}

BS concentrations were analysed in duplicate after dilution with distilled water (1:50) at the Central Laboratory of the Norwegian School of Veterinary Science (Oslo, Norway) using Advia ${ }^{\circledR} 1650$ (Bayer HealthCare), an automated analysis system for clinical chemistry. Principles of analyses were based on enzymatic amplification determining total $3 \alpha$-hydroxy bile acids using a kit (Bio-Stat Diagnostic systems). In the presence of Thio-NAD, the enzyme $3 \alpha$-hydroxysteroid dehydrogenase converts bile acids to 3-keto steroids and Thio-NADH. The rate of formation of Thio-NADH was measured spectrophotometrically at $410 \mathrm{~nm}$. BS concentration was determined using a standard curve of known concentrations of taurocholic acid.

\section{Statistical analyses}

Data are presented as means and standard deviations. Student's $t$ test (two-sample, assuming unequal variance) was used to estimate significant differences (GraphPad Prism $\times 6$ ). Differences were considered as significant when $P<0 \cdot 05$.

\section{Results}

The lipid composition of SO is described in Table 1, containing approximately 6\% EPA (20:5) and 9\% DHA (22:6).
The other main FA of SO were 16:0, 18:1n-9 and 18:2, constituting of 13,28 and $9 \%$, respectively.

The amount of the released FA from TAG, using the commercial porcine $\mathrm{PB}$, was substrate-dependent, as shown in Fig. 1. Incubation of $15.5 \mathrm{mg} \mathrm{SO} / \mathrm{ml} \mathrm{PB}$ released 417 (SD 29) $\mathrm{mg} \mathrm{NEFA} / \mathrm{g} \mathrm{SO}$, which was significantly higher than $4.4 \mathrm{mg} \quad \mathrm{SO} / \mathrm{ml} \quad \mathrm{PB} \quad(P=0.0010)$ and $7.0 \mathrm{mg} \quad \mathrm{SO} / \mathrm{ml} \quad \mathrm{PB}$ $(P=0.0144)$, resulting in a release of 235 (SD 22) and 246 (SD 6) $\mathrm{mg} \mathrm{NEFA} / \mathrm{g} \mathrm{SO}$, respectively (Fig. 1). A further increase in $\mathrm{SO}$ to $38.0 \mathrm{mg} \mathrm{SO} / \mathrm{ml} \mathrm{PB}$ did not give a significant increase in the release of FA compared with $15.5 \mathrm{mg} \mathrm{SO} / \mathrm{ml} \mathrm{PB}$ (result not shown).

BS were added to pancreatin $(1.4 \mathrm{mg} / \mathrm{ml})$ in concentrations ranging from 0 to $11.8 \mathrm{~mm}$, resulting in a 4 -fold increase in the liberation of total FA (Fig. 2(a)), from 24.6 to $220 \mathrm{mg} \mathrm{NEFA} / \mathrm{g}$ SO. No significant difference was observed at a BS concentration of $11.8 \mathrm{~mm}$ while increasing pancreatin from 1.4 to $13.6 \mathrm{mg} / \mathrm{ml}$ (Fig. 2(a) and (b)). A ten times increase in PB concentration $(13.6 \mathrm{mg}$ pancreatin/ $\mathrm{ml}$ and $118.0 \mathrm{~mm}-\mathrm{BS}$ ) only increased NEFA liberation by a factor of 2, from 241 (SD 16) to 496 (SD 87) $\mathrm{mg}$ NEFA/g SO (Fig. 2(b)). This experiment demonstrates a highly BS-dependent lipolysis by the porcine enzyme system (pancreatin), contrary to the human lipolytic enzyme system (HDJ) (Fig. 3).

The in vitro digestion was carried out for $110 \mathrm{~min}$, indicating that the release of FA reached a plateau at $80 \mathrm{~min}$ using both enzyme systems. Due to the lack of parallels, data obtained at $110 \mathrm{~min}$ are not shown, but the results confirmed the plateau. After $80 \mathrm{~min}$ of incubation, both PB (11.8 mm-BS) and HDJ (1.4 mm-BS) liberated approximately the same total amount of FA (352 (SD 23) and 379 (SD 18) mg NEFA/g SO, respectively), indicating about $67 \%$ hydrolysis (from $s n-1$ and $s n-3$ ) of TAG in the substrate added (Fig. 4). There was no significant difference in the kinetics of liberation between the two lipolytic enzyme sources, $\mathrm{PB}$ and $\mathrm{HDJ}$, releasing 189 (SD 24) and 173 (SD 24) $\mathrm{mg} \mathrm{NEFA} / \mathrm{g}$ SO at $20 \mathrm{~min}, 253$ (SD 15) and 257 (SD 35) $\mathrm{mg}$ NEFA/g SO at $40 \mathrm{~min}$ and 318 (SD 16) and 312 (SD 11) $\mathrm{mg} \mathrm{NEFA/g} \mathrm{SO}$ at $60 \mathrm{~min}$, respectively.

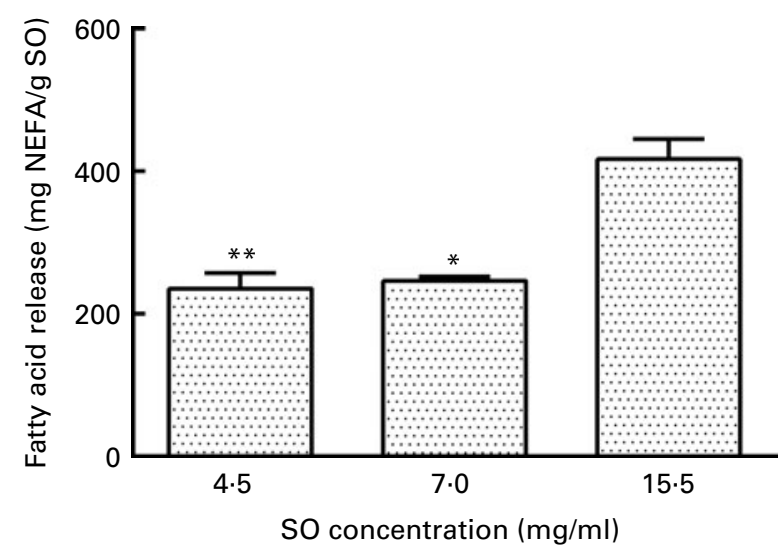

Fig. 1. Effect of the substrate (salmon oil; SO) concentration on release of fatty acids (FA; mg NEFA/g SO) measured after incubation at $37^{\circ} \mathrm{C}$ for $80 \mathrm{~min}$, using a commercial pancreatin plus bile. Values are means, with standard deviations represented by vertical bars. Mean value was significantly different from that following incubation of $S O$ at $15.5 \mathrm{mg} / \mathrm{ml}$ : ${ }^{\star} P=0.0144,{ }^{* \star} P=0.0010$. 

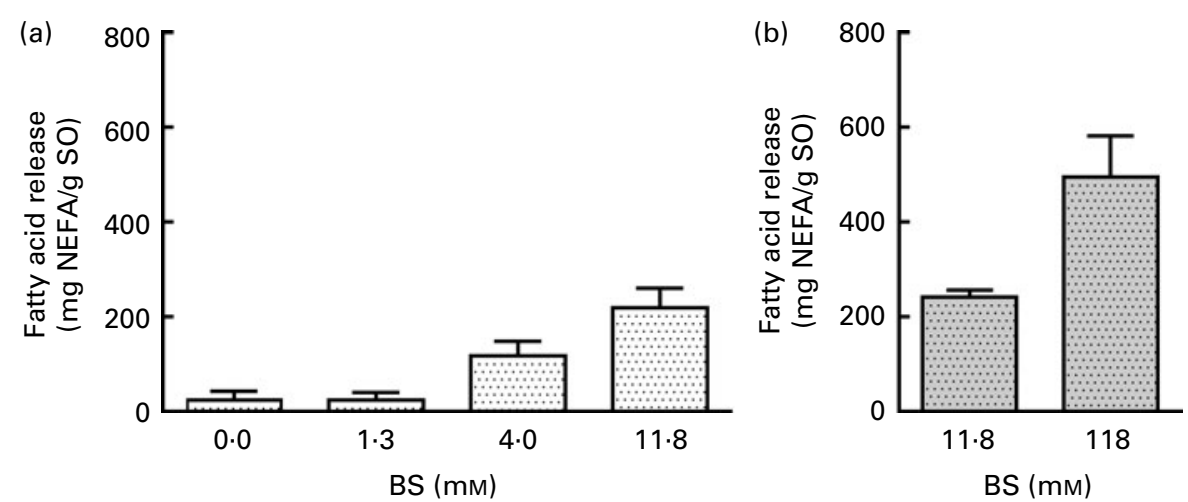

Fig. 2. Effect of bile salt (BS) concentration on the release of fatty acids (FA; mg NEFA/g salmon oil (SO)) measured after incubation at $37^{\circ} \mathrm{C}$ for 80 min. Commercial pancreatin are used as the lipolytic enzyme source in two different concentrations: (a) $1.36 \mathrm{mg} / \mathrm{ml}$ and (b) $13.6 \mathrm{mg} / \mathrm{ml}$. Values are means, with standard deviations represented by vertical bars.

However, the release of specific FA was found to be different for some of the FA analysed (Table 2). Fig. 5 shows the significant differences found at $60 \mathrm{~min}$ when the level of overall hydrolysis caused by HDJ was similar to PB (Fig. 4) and the data therefore primarily reflecting selective hydrolysis. Compared with $\mathrm{PB}$, HDJ caused a significantly higher release of EPA at all times $(P<0.05)$, and the release of DHA was found to be significantly higher at $60(P=0.0417)$ and $80 \mathrm{~min}$ $(P=0.0380)$ (Table 2). HDJ also gave a higher release of $18: 2$ at $20 \mathrm{~min}(P=0.0394), 60 \mathrm{~min}(P=0.0299)$ and $80 \mathrm{~min}$ $(P=0.0268)$, and of $16: 0$ at $60 \mathrm{~min}(P=0.0235)$. On the other hand, PB showed a significantly higher ability to release $16: 1$ $(P=0.0471), 20: 1(P=0 \cdot 0177)$ and $22: 1(P=0 \cdot 0177)$ at $60 \mathrm{~min}$ (Table 2$)$. Furthermore, the results showed that both enzyme preparations released approximately the same amounts of other FA (constituting <3.5\%). A significantly higher ability for HDJ to release EPA compared with DHA was observed throughout the in vitro digestion, at $20 \quad(P=0.0054), 40$ $(P=0.0058), 60(P=0.0003)$ and $80(P=0.0409) \mathrm{min}$.

\section{Discussion}

The present study show a similar total lipolytic activity during the in vitro digestion of SO using two different enzyme sources: HDJ and a commercial porcine PB. The total protein content $(1.37 \mathrm{mg}$ protein $/ \mathrm{ml})$ was the same in both enzyme preparations, ensuring similar enzyme concentrations. The release of FA, measured as NEFA, reached a plateau at $80 \mathrm{~min}$, indicating that $67 \%$ of the accessible FA were hydrolysed from TAG in SO (Fig. 4.), which is higher than that reported in other in vitro studies often showing less than $44 \%$ release of $\mathrm{FA}^{(55,56)}$. However, it is still lower than what is assumed to be digested and absorbed in vivo $(98 \%)^{(27)}$. The lower outcome measured in the release of FA from TAG observed in static in vitro digestion compared with in vivo may be explained by saturated micellar solubilisation of lipolytic products, obstructing the interaction between pancreatic lipase and the substrate ${ }^{(5)}$. During in vitro lipolysis, there will be an accumulation of NEFA, which may lead to equilibrium between the substrate and the product ${ }^{(57)}$, giving a so-called product inhibition. To avoid this, certain dynamic in vitro digestion models have been developed using dialysis to extract the digested components, which closely approximates absorption through the lining of the gut in vivo ${ }^{(58)}$.

To ensure maximum hydrolytic activity in the present in vitro model, optimal physiological concentrations of the enzymes and BS were determined. Droplet size of the emulsion is important when studying lipid digestion due to the surface activity of pancreatic lipase ${ }^{(8)}$. In the present study, a rotary incubator was used to simulate the movement of the gastrointestinal tract and to ensure similar conditions when comparing the two lipolytic enzyme systems. Standard variations within each enzyme system were low $(<10 \%)$, showing that the heterogeneous nature of the mixture gave reproducible results. However, there were other physiologically relevant parameters that were not included in the model. It has been reported that lingual and gastric lipase systems may be responsible for approximately 10-30\% of lipid hydrolysis ${ }^{(20,21)}$. Their activity occur mainly in the gastric ventricle, and facilitates the following TAG hydrolysis by HPL better by improving emulsification with $\mathrm{BS}^{(19,20,37)}$. The static in vitro duodenal digestion model used in the present experiment was made to mimic lipid digestion in the duodenum, and the gastric step was not included. Pancreatic lipase was therefore the sole enzyme responsible for lipolytic activity.

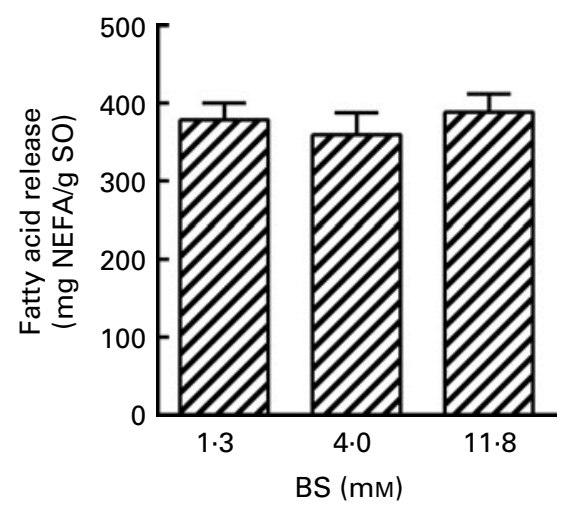

Fig. 3. Effect of bile salt (BS) concentration on the release of fatty acids (FA; mg NEFA/g salmon oil (SO)) after incubation at $37^{\circ} \mathrm{C}$ for $80 \mathrm{~min}$, using human duodenal juice as a lipolytic enzyme source. Values are means, with standard deviations represented by vertical bars. 


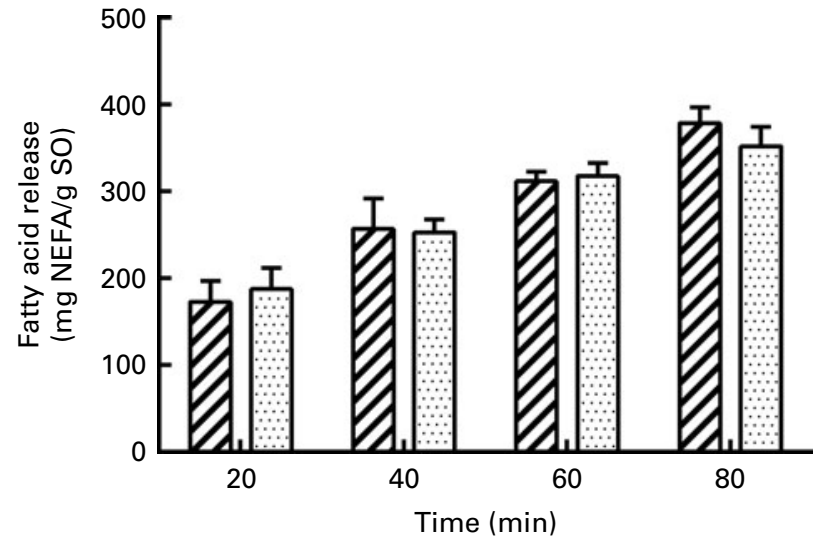

Fig. 4. Release of total fatty acids (FA; mg NEFA/g salmon oil (SO)) measured after incubation at $37^{\circ} \mathrm{C}$ for $80 \mathrm{~min}$ using porcine pancreatin and bile $(\forall)$ and human duodenal juice $(\mathbb{Z})$ as lipolytic enzyme sources. Values are means, with standard deviations represented by vertical bars.

However, for the aspirated HDJ, there is a possibility for the leakage of gastric lipase from the gastric juice because of the procedure used ${ }^{(51)}$. Gastric lipase has a lower $\mathrm{pH}$ optimum than pancreatic lipase $\left(4^{(59)}\right.$ and $6 \cdot 5-7 \cdot 5^{(60)}$, respectively), which makes it unlikely that gastric lipase has contributed in the liberation of FA in these experiments which is conducted at $\mathrm{pH} 7 \cdot 0$.

Changes in $\mathrm{pH}$ will affect enzyme activity and alter its efficiency. In the small intestine, $\mathrm{pH}$ gradually increases from 6 to $7 \cdot 4^{(61)}$ due to the breakdown and degradation of different food constituents, e.g. hydrolysed FA from TAG ${ }^{(62)}$. In the present study, $\mathrm{pH}$ was set to $7 \cdot 0$ and controlled both at 0 and $80 \mathrm{~min}$. There were no changes in $\mathrm{pH}$ through digestion (results not shown), probably due to high buffer capacity in the in vitro system. The change in $\mathrm{pH}$ due to lipid hydrolysis was therefore not probably affecting the rate of lipolysis in the present experiment.

The positive impact of BS on lipase activity is well known ${ }^{(36)}$. Concentrations of total BS are found to be approximately $2.6 \mathrm{~mm}$ in the fasted state $^{(63)}$ and increase to approximately $11-14.5 \mathrm{~mm}$ in response to a meal ${ }^{(20,63,64)}$. This observation is compatible with BS concentration found in HDJ used in these studies, which has an average of $1.3 \mathrm{~mm}^{(50)}$ and is aspirated from semi-fasted subjects. The standard PB mix used contains $11.8 \mathrm{~mm}-\mathrm{BS}$, which is in the normal range in the 'fed state'. On the basis of this finding, there is reason to believe that lipolytic activity in $\mathrm{PB}$ would be higher compared with the lipolytic activity of HDJ, which reflects a 'fasted state'. However, the influence of BS concentration was different in the two enzyme preparations (Figs. 2(a) and (b) and 3). While porcine pancreatin showed increased activity with increasing BS concentration, the lipase activity of HDJ was constant. These results indicate that both HDJ and PB had optimal conditions for lipolytic activity, and that the experiments determining total lipid breakdown are comparable despite the different BS concentrations. The limited effect of BS on the lipolytic activity of HDJ might be due to several factors. The release of FA with $1.3 \mathrm{~mm}$-BS may already have reached the equilibrium in the in vitro digestion system, due to higher enzyme activity. Furthermore, HDJ consists of pancreatic juice and bile, in addition to secretions from the gastrointestinal tract, in contrast to porcine pancreatin which is made from grinded pancreas. This might lead to HDJ having a higher share of other components, e.g. phospholipids and cholesterol, which could act as emulsifiers. The requisite of BS to optimise the lipolytic enzyme system in HDJ might therefore be lower. Both are plausible explanations and need to be further examined.

Previous studies have reported the specific positions of FA on TAG in marine oils ${ }^{(65)}$. The results from these studies showed that $16: 1,18: 1,20: 1$ and $22: 1$ are mainly found in the $s n-1$ and $s n-3$ positions $(>70 \%)$, whereas 14:0 (approximately 50\%), 16:0 (approximately 45\%) EPA (20:5, approximately 47\%), DHA (22:6, approximately 76\%) are mainly found in the $s n-2$ position. Even though 14:0, 16:0 and EPA are mostly found in the $s n-2$ position, these FA are, together with 18:2, more randomly distributed in all the

Table 2. Release of specific fatty acids (FA) (\% of total FA in salmon oil) during digestion with commercial pancreatine and bile (PB) and human duodenal juice (HDJ)

\begin{tabular}{|c|c|c|c|c|}
\hline FA & Time (min) & HDJ (\%) & PB (\%) & $P$ \\
\hline \multirow[t]{4}{*}{$14: 0$} & 20 & 14 & 17 & 0.4264 \\
\hline & 40 & 22 & 23 & 0.9367 \\
\hline & 60 & 28 & 30 & 0.2710 \\
\hline & 80 & 34 & 33 & 0.8695 \\
\hline \multirow[t]{4}{*}{$16: 0$} & 20 & 28 & 22 & 0.1939 \\
\hline & 40 & 37 & 29 & 0.1307 \\
\hline & 60 & 44 & 38 & $0.0235^{\star}$ \\
\hline & 80 & 52 & 42 & 0.1104 \\
\hline \multirow[t]{4}{*}{$16: 1$} & 20 & 14 & 18 & $0 \cdot 2428$ \\
\hline & 40 & 22 & 24 & 0.5754 \\
\hline & 60 & 27 & 30 & $0.0471^{*}$ \\
\hline & 80 & 33 & 34 & 0.7247 \\
\hline \multirow[t]{4}{*}{$18: 1$} & 20 & 15 & 20 & 0.1343 \\
\hline & 40 & 24 & 26 & 0.5077 \\
\hline & 60 & 29 & 32 & 0.2891 \\
\hline & 80 & 35 & 35 & $>0.9999$ \\
\hline \multirow[t]{4}{*}{$18: 2$} & 20 & 26 & 19 & $0.0394^{*}$ \\
\hline & 40 & 32 & 24 & 0.0687 \\
\hline & 60 & 37 & 29 & $0.0299^{*}$ \\
\hline & 80 & 43 & 33 & $0.0268^{*}$ \\
\hline \multirow{4}{*}{$18: 3$} & 20 & 11 & 13 & 0.2271 \\
\hline & 40 & 16 & 17 & 0.6437 \\
\hline & 60 & 20 & 22 & 0.3090 \\
\hline & 80 & 25 & 24 & 0.6346 \\
\hline \multirow{4}{*}{$20: 1$} & 20 & 16 & 20 & 0.1397 \\
\hline & 40 & 25 & 29 & $0 \cdot 2112$ \\
\hline & 60 & 31 & 37 & $0.0177^{*}$ \\
\hline & 80 & 38 & 40 & 0.6303 \\
\hline \multirow[t]{4}{*}{$22: 1$} & 20 & 21 & 31 & 0.0517 \\
\hline & 40 & 38 & 43 & 0.3405 \\
\hline & 60 & 46 & 53 & $0.0177^{*}$ \\
\hline & 80 & 55 & 58 & 0.6731 \\
\hline \multirow[t]{4}{*}{$20: 5$} & 20 & 7 & 4 & $0.0028^{\star \star}$ \\
\hline & 40 & 9 & 6 & $0.0076^{\star \star}$ \\
\hline & 60 & 12 & 7 & $0.0039^{\star \star}$ \\
\hline & 80 & 14 & 9 & $0.0264^{*}$ \\
\hline \multirow[t]{4}{*}{$22: 6$} & 20 & 5 & 4 & 0.0535 \\
\hline & 40 & 7 & 6 & 0.0833 \\
\hline & 60 & 8 & 7 & $0.0417^{*}$ \\
\hline & 80 & 11 & 9 & $0.0380^{*}$ \\
\hline
\end{tabular}

${ }^{\star} P<0.05,{ }^{\star \star} P<0.01$. 


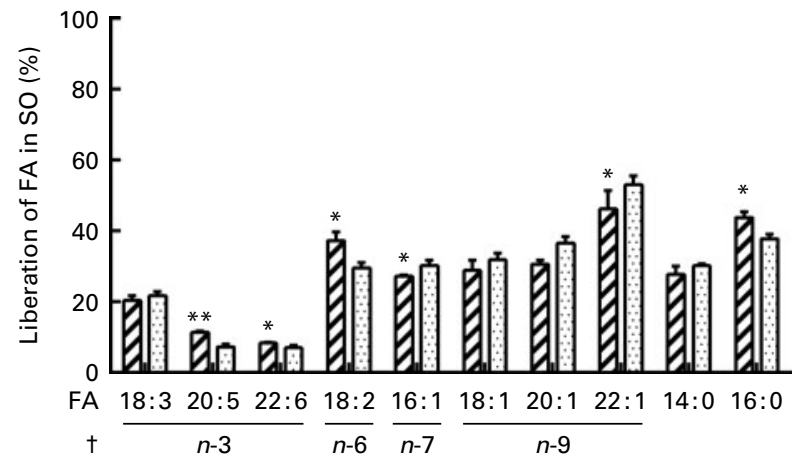

Fig. 5. Release of specific fatty acids (FA; \%) per g FA in salmon oil (SO) added after incubation at $37^{\circ} \mathrm{C}$ for $60 \mathrm{~min}$, using commercial pancreatin and bile $(\mathrm{PB}, \mathrm{G})$ and human duodenal juice (HDJ, $\mathrm{r}$ ) as the lipolytic enzyme source. Values are means, with standard deviations represented by vertical bars. ${ }^{*} / *$ Mean value was significantly different $(P<0.05 / P<0.01)$ from that following incubation with $\mathrm{PB}(20: 5, P=0.0039 ; 22: 6, P=0.0417 ; 18: 2$, $P=0.0299 ; 16: 1, P=0.0471 ; 22: 1, P=0.0177 ; 16: 0, P=0.0235)$. tWhere the first double bond in the FA is found (counted from the $-\mathrm{COOH}$ ).

$s n$ positions than other FA on TAG. The positions of FA in marine oils and the known HPL position preference ${ }^{(34,35)}$ are in accordance with the results from the present study, demonstrating that the FA found in the $s n-1$ and $s n-3$ positions are released to a higher degree than the FA mainly found in the $s n-2$ position (Fig. 5). Furthermore, previous studies have shown that PUFA containing double bonds close to the carboxyl group are more resistant to attack by pancreatic lipases ${ }^{(66)}$. In EPA and DHA, the first double bond is at carbon number three $(n-3)$, which might also explain why the release of these FA is relatively low at $80 \mathrm{~min}(10-14 \%)$ when compared with the other FA analysed (33-58\%). These observations could also explain the differences between the observed effect of the positioning of FA on TAG, explaining why $14: 0$ and $16: 0$, found in the $s n-2$ position, seem to be released to the same degree as the FA found in the $s n-1$ and $s n-3$ positions. On the basis of these observations, it is likely that both the position of the FA on TAG and the appearance of double bonds in the FA affect both lipolytic enzyme systems.

Although no differences in total lipolytic activity were observed between HDJ and PB, the present results show significant differences in the hydrolysis of specific FA, suggesting that lipases of different origins may have different affinities to specific TAG or FA. Variations in the levels of overall hydrolysis might lead to the masking of selective hydrolysis. However, observed variations were small, and at $60 \mathrm{~min}$ when HDJ and PB caused almost identical levels of hydrolysis, the difference in the release of various FA was most pronounced. When taking all time points into account, HDJ gave, in general, a higher release of the PUFA 18:2, EPA and DHA. The digestion of long-chain FA, including the transport and distribution of its derived products in the body, is complex. Some studies have concluded that they are poorly broken down in the small intestine, demonstrating slow adsorption and recovery in the circulation postprandially ${ }^{(66-68)}$, whereas others have shown an efficient recovery of FA from marine oils in the adipose tissue as well as the mobilisation of these FA from the adipose tissue $^{(69,70)}$. EPA and DHA are two of the PUFA which have been extensively studied, due to their potential health benefits. However, to our knowledge, no studies on the digestion and release of these specific $n$ - 3 LC-PUFA in the small intestine have been reported. In salmon, EPA is randomly distributed on the glycerol backbone, whereas DHA is detected mostly in the $s n$ - 2 position ${ }^{(71-74)}$. In the present experiment using HDJ, a higher release was observed for EPA compared with DHA, $14 \%$ against $10 \%$ at $80 \mathrm{~min}$, respectively. This difference may partly be explained by pancreatic lipase position specificity, which is the $s n-1$ and $s n-3$ positions of $\mathrm{TAG}^{(39,40)}$. The significantly higher portion of EPA released from TAG, observed in the present study, may partly explain the higher increase in circulating EPA compared with DHA, despite similar intakes, observed in human intervention studies $^{(75-78)}$. This has previously been explained with a more strict biological regulation of DHA levels ${ }^{(78)}$. FA in the $s n-2$ position on TAG will be metabolised as monoacylglycerol and therefore are probably subjected to different metabolic pathways. The results from the present study showed that the differences between EPA and DHA might not just be due to different metabolism in the body after absorption, but also due to a specific preference of human pancreatic lipase in the release of the two different FA in the intestinal lumen. The present results also indicated that HDJ and PB had different impacts on the release of EPA and DHA. PB released $9 \%$ of both FA at $80 \mathrm{~min}$, whereas HDJ released 14\% EPA and $10 \%$ DHA. Whether this is due to porcine enzymes in PB releasing FA also from the $s n-2$ position needs to be further investigated. HDJ also gave a significantly higher release of the PUFA 18:2 compared with PB. 18:2 is a precursor for the formation of the $n$-6 LC-PUFA arachidonic acid (20:4), known to be important for various physiological reactions in the body ${ }^{(79,80)}$. The effect and reason for the specific release of $18: 2$ needs to be further examined.

\section{Conclusion and summary}

In the present study, we examined the possibility to mimic an in vitro digestion model with human gastrointestinal juices (HDJ), using a commercial enzyme preparation consisting of porcine pancreatine and bile (PB). This was successful, and we were able to adjust the model by giving the same total liberation and the kinetics using both enzyme sources. A $67 \%$ release of the available FA in SO was obtained, showing that the substrate and enzyme ratios, as well as the BS concentration used, were suitable for performing in vitro lipid digestion studies. Despite similar total lipolytic activity, HDJ and PB gave significant different liberation of specific FA. A higher release of EPA and DHA was obtained using HDJ, showing that the human lipolytic enzyme system might be better suited to release $n$-3 LC-PUFA known to have several positive implications on health. The results also showed that HDJ gave a significant higher release of EPA compared with DHA, which could be explained by enzyme specificity both for the specific FA per $s e$ and to the position on TAG. 


\section{Acknowledgements}

The present study was supported by the Research Council of Norway, and carried out at the University of Life Sciences and Nofima, both located at Aas, Norway. We also wish to thank the Oestfold Hospital Trust for supplying the possibility for aspirating human gastric and duodenal juices from human volunteers. The authors are participants in the FA1005 COST Action INFOGEST on food digestion. K. E. A. was involved in the planning, conducting of the experiments and writing of the paper. B. K. participated in the planning, discussion and revision of the paper. H. H. participated in the discussion and revision of the paper. G. V. contributed to the planning a part of the experiments and the discussion of the results. M. J. was responsible for the aspiration of the gastrointestinal juices. G. E. V. contributed to the planning, discussion and revision of the paper. The authors report no conflict of interest and are alone responsible for the content and writing of the manuscript.

\section{References}

1. Hur SJ, Lim BO, Decker EA, et al. (2011) In vitro human digestion models for food applications. Food Chem 125, $1-12$.

2. Fatouros DG \& Mullertz A (2008) In vitro lipid digestion models in design of drug delivery systems for enhancing oral bioavailability. Expert Opin Drug Metab Toxicol 4, 65-76.

3. Almaas H, Holm H, Langsrud T, et al. (2006) In vitro studies of the digestion of caprine whey proteins by human gastric and duodenal juice and the effects on selected microorganisms. Br J Nutr 96, 562-569.

4. Eriksen EK, Holm H, Jensen E, et al. (2010) Different digestion of caprine whey proteins by human and porcine gastrointestinal enzymes. Br J Nutr 104, 374-381.

5. Almaas H, Eriksen E, Sekse C, et al. (2011) Antibacterial peptides derived from caprine whey proteins, by digestion with human gastrointestinal juice. Br J Nutr 106, 896-905.

6. Faye T, Tamburello A, Vegarud GE, et al. (2012) Survival of lactic acid bacteria from fermented milks in an in vitro digestion model exploiting sequential incubation in human gastric and duodenum juice. J Dairy Sci 95, 558-566.

7. Miled N, Canaan S, Dupuis L, et al. (2000) Digestive lipases: from three-dimensional structure to physiology. Biochimie 82, 973-986.

8. Wilde PJ \& Chu BS (2011) Interfacial, colloidal aspects of lipid digestion. Adv Colloid Interface Sci 165, 14-22

9. Uauy R \& Valenzuela A (2000) Marine oils: the health benefits of $n$-3 fatty acids. Nutrition 16, 680-684.

10. Calder PC (2004) n-3 Fatty acids and cardiovascular disease: evidence explained and mechanisms explored. Clin Sci (Lond) 107, 1-11.

11. Calder PC (2006) n-3 Polyunsaturated fatty acids, inflammation, and inflammatory diseases. Am J Clin Nutr $\mathbf{8 3}$, 1505S-1519S.

12. Mozaffarian D (2008) Fish and $n$-3 fatty acids for the prevention of fatal coronary heart disease and sudden cardiac death. Am J Clin Nutr 87, 1991S-1996S.

13. Cunnane SC, Plourde M, Pifferi F, et al. (2009) Fish, docosahexaenoic acid and Alzheimer's disease. Prog Lipid Res $\mathbf{4 8}$ 239-256.

14. Appleton KM, Rogers PJ \& Ness AR (2010) Updated systematic review and meta-analysis of the effects of $n-3$ long-chain polyunsaturated fatty acids on depressed mood. Am J Clin Nutr 91, 757-770.

15. Ackman RG (1989) Nutritional composition of fats in seafoods. Prog Food Nutr Sci 13, 161-289.

16. McClements DJ \& Li Y (2010) Review of in vitro digestion models for rapid screening of emulsion-based systems. Food Funct 1, 32-59.

17. Carey MC, Small DM \& Bliss CM (1983) Lipid digestion and absorption. Annu Rev Physiol 45, 651-677.

18. Hernell O, Staggers JE \& Carey MC (1990) Physical-chemical behavior of dietary and biliary lipids during intestinal digestion and absorption. 2. Phase analysis and aggregation states of luminal lipids during duodenal fat digestion in healthy adult human beings. Biochemistry 29, 2041-2056.

19. Armand M, Borel P, Dubois C, et al. (1994) Characterization of emulsions and lipolysis of dietary lipids in the human stomach. Am J Physiol 266, G372-G381.

20. Armand M, Borel P, Pasquier B, et al. (1996) Physicochemical characteristics of emulsions during fat digestion in human stomach and duodenum. Am J Physiol 271, G172-G183.

21. Pafumi Y, Lairon D, de la Porte PL, et al. (2002) Mechanisms of inhibition of triacylglycerol hydrolysis by human gastric lipase. J Biol Chem 277, 28070-28079.

22. Tsuzuki W, Ue A, Nagao A, et al. (2004) Inhibitory effect of lysophosphatidylcholine on pancreatic lipase-mediated hydrolysis in lipid emulsion. Biochim Biophys Acta 1684, 1-7.

23. Mun S, Decker EA \& McClements DJ (2007) Influence of emulsifier type on in vitro digestibility of lipid droplets by pancreatic lipase. Food Res Int 40, 770-781.

24. McClements DJ, Decker EA, Park Y, et al. (2008) Designing food structure to control stability, digestion, release and absorption of lipophilic food components. Food Biophys 3, 219-228.

25. Singh H, Ye A \& Horne D (2009) Structuring food emulsions in the gastrointestinal tract to modify lipid digestion. Prog Lipid Res 48, 92-100.

26. Gallier S \& Singh H (2012) Behavior of almond oil bodies during in vitro gastric and intestinal digestion. Food Funct 3, 547-555.

27. Armand M (2007) Lipases and lipolysis in the human digestive tract: where do we stand? Curr Opin Clin Nutr Metab Care 10, 156-164.

28. Abrams CK, Hamosh M, Lee TC, et al. (1988) Gastric lipase: localization in the human stomach. Gastroenterology $\mathbf{9 5}$, $1460-1464$.

29. Moreau H, Laugier R, Gargouri Y, et al. (1988) Human preduodenal lipase is entirely of gastric fundic origin. Gastroenterology 95, 1221-1226.

30. Hamosh M, Ganot D \& Hamosh P (1979) Rat lingual lipase. Characteristics of enzyme activity. J Biol Chem 254, 12121-12125.

31. Patton JS \& Carey MC (1979) Watching fat digestion. Science 204, 145-148.

32. Tiruppathi C \& Balasubramanian KA (1982) Purification and properties of an acid lipase from human gastric juice. Biochim Biophys Acta 712, 692-697.

33. Patton JS, Rigler MW, Liao TH, et al. (1982) Hydrolysis of triacylglycerol emulsions by lingual lipase. A microscopic study. Biochim Biophys Acta 712, 400-407.

34. Carriere F, Barrowman JA, Verger R, et al. (1993) Secretion and contribution to lipolysis of gastric and pancreatic lipases during a test meal in humans. Gastroenterology 105, 876-888.

35. Hayes RJ, Pence DH, Scheinbach S, et al. (1994) Review of triacylglycerol digestion, absorption, and metabolism with respect to Salatrim triacylglycerols. J Agric Food Chem $\mathbf{4 2}$, $474-483$. 
36. Reis $\mathrm{P}$, Holmberg $\mathrm{K}$, Watzke $\mathrm{H}$, et al. (2009) Lipases at interfaces: a review. Adv Colloid Interface Sci 147-148, $237-250$.

37. Gargouri Y, Pieroni G, Riviere C, et al. (1986) Importance of human gastric lipase for intestinal lipolysis: an in vitro study. Biochim Biophys Acta 879, 419-423.

38. Porsgaard T, Xu X, Gottsche J, et al. (2005) Differences in the intramolecular structure of structured oils do not affect pancreatic lipase activity in vitro or the absorption by rats of (n-3) fatty acids. J Nutr 135, 1705-1711.

39. Mattson FH, Benedict JH, Martin JB, et al. (1952) Intermediates formed during the digestion of triglycerides. J Nutr $\mathbf{4 8}$, 335-344.

40. Rogalska E, Ransac S \& Verger R (1990) Stereoselectivity of lipases. II. Stereoselective hydrolysis of triglycerides by gastric and pancreatic lipases. J Biol Chem 265 , 20271-20276.

41. Mattson FH \& Volpenhein RA (1964) The digestion and absorption of triglycerides. J Biol Chem 239, 2772-2777.

42. Borgstrom B \& Erlanson C (1971) Pancreatic juice co-lipase: physiological importance. Biochim Biophys Acta 242, 509-513.

43. Lairon D, Nalbone G, Lafont H, et al. (1978) Inhibition of lipase adsorption at interfaces. Role of bile salt micelles and colipase. Biochemistry 17, 205-208.

44. Reis P, Watzke H, Leser M, et al. (2010) Interfacial mechanism of lipolysis as self-regulated process. Biophys Chem 147, 93-103.

45. Morgan RG \& Hoffman NE (1971) The interaction of lipase, lipase cofactor and bile salts in triglyceride hydrolysis. Biochim Biophys Acta 248, 143-148.

46. Freie AB, Ferrato F, Carriere F, et al. (2006) Val-407 and Ile-408 in the beta5'-loop of pancreatic lipase mediate lipase-colipase interactions in the presence of bile salt micelles. J Biol Chem 281, 7793-7800.

47. Donner J, Spink CH, Borgstom B, et al. (1976) Interactions between pancreatic lipase, co-lipase, and taurodeoxycholate in the absence of triglyceride substrate. Biochemistry $\mathbf{1 5}$, 5413-5417.

48. Patton JS, Albertsson PA, Erlanson C, et al. (1978) Binding of porcine pancreatic lipase and colipase in the absence of substrate studies by two-phase partition and affinity chromatography. J Biol Chem 253, 4195-4202.

49. Borgstrom B, Erlanson-Albertsson C \& Wieloch T (1979) Pancreatic colipase: chemistry and physiology. J Lipid Res 20, 805-816.

50. Ulleberg EK, Comi I, Holm H, et al. (2011) Human gastrointestinal juices intended for use in in vitro digestion models. Food Dig 2, 52-61.

51. Holm H, Krogdahl A \& Hanssen LE (1988) High and low inhibitor soybean meals affect human duodenal proteinase activity differently: in vitro comparison of proteinase inhibition. J Nutr 118, 521-525.

52. Aura AM, Harkonen H, Fabrititus M, et al. (1999) Development of an in vitro enzymic digestion method for removal of starch and protein and assessment of its performance usin rye and wheat breads. J Cereal Sci 29, 139-152.

53. Bligh EG \& Dyer WJ (1959) A rapid method for total lipid extraction and purification. Can J Biochem Physiol 37, 911-917.

54. Ruiz J, Antequera T, Andres AI, et al. (2004) Improvement of a solid phase extraction method for analysis of lipid fractions in muscle foods. Anal Chim Acta 520, 201-205.

55. Martin D, Nieto-Fuentes JA, Señoráns FJ, et al. (2010) Intestinal digestion of fish oils and $n-3$ concentrates under in vitro conditions. Eur J Lipid Sci Technol 112, 1315-1322.
56. Larsson K, Cavonius L, Alminger M, et al. (2012) Oxidation of cod liver oil during gastrointestinal in vitro digestion. J Agric Food Chem 60, 7556-7564.

57. Reis PM, Raab TW, Chuat JY, et al. (2008) Influence of surfactants on lipase fat digestion in a model gastro-intestinal system. Food Biophys 3, 370-381.

58. Minekus M, Marteau P, Habenaar R, et al. (1995) A multicompartmental dynamic computer-controlled model simulating the stomach and small intestine. Alternat Lab Anim 23, 197-209.

59. Carriere F, Gargouri Y, Moreau H, et al. (1994) Gastric lipases: cellular, biochemical and kinetic aspects. In Lipases: Their Structure, Biochemistry and Application, pp. 181-205 [P Woolley, editor]. New York: Cambridge University Press.

60. Moreau H, Gargouri Y, Lecat D, et al. (1988) Screening of preduodenal lipases in several mammals. Biochim Biophys Acta 959, 247-252.

61. Fallingborg J (1999) Intraluminal pH of the human gastrointestinal tract. Dan Med Bull 46, 183-196.

62. Rudman D \& Shank PW (1966) Observations on the production of hydrogen ions during mobilization of fatty acids from adipose tissue. Endocrinology 79, 1100-1108.

63. Kalantzi L, Goumas K, Kalioras V, et al. (2006) Characterization of the human upper gastrointestinal contents under conditions simulating bioavailability/bioequivalence studies. Pharm Res 23, 165-176.

64. Fausa O (1974) Duodenal bile acids after a test meal. Scand J Gastroenterol 9, 567-570.

65. Brockerhoff H, Hoyle RJ, Hwang PC, et al. (1968) Positional distribution of fatty acids in depot triglycerides of aquatic animals. Lipids 3, 24-29.

66. Bottino NR, Vandenburg GA \& Reiser R (1967) Resistance of certain long-chain polyunsaturated fatty acids of marine oils to pancreatic lipase hydrolysis. Lipids 2, 489-493.

67. Yurkowski M \& Brockerhoff H (1966) Fatty acid distribution of triglycerides determined by deacylation with methyl magnesium bromide. Biochim Biophys Acta 125, 55-59.

68. Brockerhoff H (1970) Substrate specificity of pancreatic lipase. Influence of the structure of fatty acids on the reactivity of esters. Biochim Biophys Acta 212, 92-101.

69. Garton GA, Hilditch TP \& Meara ML (1952) The composition of the depot fats of a pig fed on a diet rich in whale oil. Biochem J 50, 517-524.

70. Storlien LH, Kraegen EW, Chisholm DJ, et al. (1987) Fish oil prevents insulin resistance induced by high-fat feeding in rats. Science $\mathbf{2 3 7}, 885-888$.

71. Amate L, Ramirez M \& Gil A (1999) Positional analysis of triglycerides and phospholipids rich in long-chain polyunsaturated fatty acids. Lipids 34, 865-871.

72. Ando Y, Satake M \& Takahashi Y (2000) Reinvestigation of positional distribution of fatty acids in docosahexaenoic acid-rich fish oil triacyl-sn-glycerols. Lipids 35, 579-582.

73. Miller MR, Nichols PD, Barnes J, et al. (2006) Regiospecificity profiles of storage and membrane lipids from the gill and muscle tissue of Atlantic salmon (Salmo salar L.) grown at elevated temperature. Lipids 41, 865-876.

74. Mbatia B, Adlercreutz D, Adlercreutz P, et al. (2010) Enzymatic oil extraction and positional analysis of $\omega-3$ fatty acids in Nile perch and salmon heads. Process Biochem $\mathbf{4 5}$, 815-819.

75. Visioli F, Rise P, Barassi MC, et al. (2003) Dietary intake of fish vs. formulations leads to higher plasma concentrations of $n$-3 fatty acids. Lipids 38, 415-418.

76. Elvevoll EO, Barstad H, Breimo ES, et al. (2006) Enhanced incorporation of $n-3$ fatty acids from fish compared with fish oils. Lipids 41, 1109-1114. 
77. Elvevoll EO, Eilertsen KE, Brox J, et al. (2008) Seafood diets: hypolipidemic and antiatherogenic effects of taurine and $n-3$ fatty acids. Atherosclerosis 200, 396-402.

78. Kirkhus B, Lamglait A, Eilertsen KE, et al. (2012) Effects of similar intakes of marine $n-3$ fatty acids from enriched food products and fish oil on cardiovascular risk markers in healthy human subjects. Br J Nutr 107, 1339-1349.
79. Mills SC, Windsor AC \& Knight SC (2005) The potential interactions between polyunsaturated fatty acids and colonic inflammatory processes. Clin Exp Immunol 142, 216-228.

80. Calder PC (2008) Polyunsaturated fatty acids, inflammatory processes and inflammatory bowel diseases. Mol Nutr Food Res 52, 885-897. 